2011-09

\title{
Tension of APEL: perceptions of higher education in further education lecturers
}

\author{
Dismore, Harriet
}

http://hdl.handle.net/10026.1/8628

10.1080/13596748.2011.602242

Research in Post-Compulsory Education

Informa UK Limited

All content in PEARL is protected by copyright law. Author manuscripts are made available in accordance with publisher policies. Please cite only the published version using the details provided on the item record or document. In the absence of an open licence (e.g. Creative Commons), permissions for further reuse of content should be sought from the publisher or author. 
Tension of APEL: perceptions of higher education in further education lecturers

Harriet Dismore, Anne McDermott, Neil Witt, Robert Stillwell, Sophie Neville and Mark Stone, University of Plymouth

Words: 7,466

Corresponding author:

Dr Harriet Dismore

Directorate of Teaching and Learning

3 Endsleigh Place

University of Plymouth

Drake Circus, Plymouth, PL4 8AA

Email: harriet.dismore@plymouth.ac.uk 


\begin{abstract}
This paper examines the perceptions of accrediting prior experiential learning (APEL) from the point of view of lecturers delivering higher education in further education institutions. Despite the fact that APEL is recognised as potentially providing a range of benefits for higher education providers, students and employers, little research has been carried out with those responsible for accreditation. Data were obtained using an online survey to collect information from lecturers about their awareness of and support for APEL. Analysis of this information reveals that confusion about the purpose and implementation remain the main barriers to APEL for this group, and that providing appropriate support for staff could be an effective mechanism for overcoming this. The implications of this study are discussed in relation to the higher education in further education context, with specific reference to the Foundation degree.
\end{abstract}

Keywords: APEL, foundation degree; higher education, further education, lecturers 


\section{Review of Literature}

The accreditation of learning and achievement is one of the central functions of higher education and providers are increasingly recognising a myriad of ways that knowledge, skills and understanding are developed (QAA 2004). Accrediting Prior Experiential Learning (APEL) refers to the process whereby knowledge, skills and abilities gained in non-formal (work-based) and informal (life experiences) learning environments are accredited (Adam 2006). However, the term APEL is often confused for two main reasons. Firstly, whilst it is generally referred to as APEL in England, the term is known elsewhere (such as in Australia) as Recognition of Prior Learning (RPL) (Pitman 2009). Secondly, it is often confused with the Accreditation of Certified Learning (APCL) which is, 'essentially the recognition of another organisation's assessment' (Scott 2010, 19). While APEL and APCL both involve prior learning, APEL involves an assessment process by the accrediting organisation.

The notion of APEL in the context of English higher education is not a new one. A prominent theory of experiential learning was developed by Kolb and colleagues, who posited that individuals create knowledge from experience rather than just received instruction. Experiential learning theory builds upon the work of eminent scholars such as John Dewey and Jean Piaget, who shared the view that learning is a holistic process resulting from transactions between person and environment (Kolb and Kolb 2005). However, a number of criticisms have been made of this theory. For example, Bergsteiner and colleagues (2010) have argued that Kolb is unclear whether the theoretical model refers to learning styles or learning stages, an important indication of whether learning is stable or flexible. Other critiques concern the validity and reliability of Kolb's Learning Styles Inventory, a tool to help learners understand their strengths and weaknesses (ibid. 2010), whilst others question where other aspects of learning such as choice and decision-making fit into the theory (Rogers 2002).

Despite this, experiential learning continues to be influential in adult learning. The rationale to recognise non-formal and informal learning is underpinned by three main tenets. The first is that we now live in a knowledge-based society in which there is a need for education and training to be more flexible and to allow people to engage and re-engage with learning 
throughout their lives (Gallacher and Feutrie 2003). The second is related to social inclusion, whereby within the formal sector there is a need to adapt, 'entry, progression and recognition requirements to take account of non-formal and informal learning' (European Commission 2001, 13). The third is economic, that APEL can save money and time if individuals avoid repeating any learning that they already know (Scott 2005a). This is not only regarded as positive for individuals but for society, by freeing educational resources as more individuals enter the labour market faster (Scott 2010). In 2004, the Quality Assurance Agency for Higher Education drafted guidelines for recognition of prior learning. These were also set in the context of an agenda for higher education that promotes lifelong learning, wider participation and social inclusion (QAA 2004). The UK lifelong learning and widening participation agenda, in particular, has been primarily concerned with skills-based vocational learning (Jackson and Jamieson 2009).

Although there has been much debate about the concept of APEL, we still know relatively little about practice. Interest in APEL has grown in recent years as it has become recognised as a key issue in lifelong learning policy within Europe (CEDEFO 2009). According to the European Commission there is a need, 'to build bridges between different learning contexts and learning forms and to facilitate access to individual pathways of learning' (European Commission 2001, 15). However, APEL remains a marginal activity for UK higher education institutions (Garnett, Portwood and Costley 2004). Where it does occur, APEL is mainly used to gain entry onto a programme and to a lesser extent, to gain credit towards the completion of a programme of study (Learning from Experience 2003). In some institutions the review of an APEL claim constitutes a funded 10-15 credit module (HEFCE 2003). However, with the rapid growth of vocational higher education programmes (particularly the Foundation degree) aimed at employees and students with substantial work experience, interest in the potential of APEL has been growing (Garnett et al. 2004).

The concept of APEL is generally regarded as problematic in higher education because it challenges perceptions of learning. The learning has normally taken place elsewhere at another time with credit awarded on the basis of evidenced learning from the experience rather than from the experience itself. The developmental process of reflecting on the 
experiences is generally considered to be worthwhile, although examples do exist of learners feeling alienated through its objectification (Trowler 1996). It is also usually unclear how the level of an individual's experiential learning is determined (Winter 1993). Crucially, decisions regarding the accreditation of evidenced learning are a matter of academic judgement (QAA 2004, 7). Concerns among lecturers about awarding credit for experience include a perception of low student demand, difficulty in ensuring validity and reliability for APEL and awarding specific grades or marks (Merrifield, Mclntyre and Osaigbovo 2000). Peters (2005) more recently reported that whilst quality and appropriate accreditation is paramount, lecturers also want APEL to be easy to assess, to be academic and to have a personal dimension.

Despite these potential barriers, a number of benefits are associated with APEL. For example, valuing and rewarding experiential learning is thought to encourage those most alienated to return to learning (Gallacher and Feutrie 2003). Earlier studies have reported that APEL builds on previous successes and in turn, increases self-esteem and motivation as well as empower the learner (Houston, Hoover and Beer 1997). APEL also offers employers the opportunity to have employees' prior work and training formally recognised whilst simultaneously contributing to further qualifications (NIACE 2008; Leitch 2006). Indeed, it is recognised that segments of the workforce are most likely to benefit from APEL within work-based learning programmes customised to meet the needs of employers (Garnett et al. 2004). Despite these possible advantages, there remains confusion about implementation (Challis 2005; Pitman 2009).

In 2000, the Learning from Experience Trust carried out a large study involving a survey and case studies with higher education institutions across England. This reported a gap between policy and practice, recommending a review of institutional APEL practices as well as staff development in all aspects of the APEL process (Merrifield et al. 2000). Little evidence has been gathered since this study, although events such as those reported on by Challis continued to show that, 'there is little practice on which to base any generalised patterns of activity' (Challis 2005, 25). Scott more recently stressed that, 'there is little strong research either to support or refute many of the claims made for APEL' (Scott 2010, 28). 


\section{Context}

The University of Plymouth Colleges (UPC) partnership used for this investigation is located in the South West of England. A geographically isolated higher education institution (HEI), the University of Plymouth supports a network of 18 partner institutions across the region, including further education colleges and other organisations such as the Royal Navy. Provision had grown to more than 10,500 students in 2010 , approximately a third of the total number of students at the University of Plymouth. The majority of these students are studying Foundation degrees and have the opportunity to progress to the University where they can proceed to the final year of a Bachelor's degree.

Foundation degrees are higher education qualifications delivered in further education institutions currently attracting a sharp increase in enrolment. In 2007-08 there were approximately 72,000 students nationally enrolled on Foundation degrees and this has risen to 99,475 in 2010 (HEFCE 2010). Generally, these qualifications attract people from a broad range of backgrounds, particularly low participation neighbourhoods and those over 21 years old on entry. Foundation degrees (and their constituent programmes e.g. Certificate in Personal and Professional Development, Certificate in Higher Education) aim to attract 'non-traditional learners' and naturally lend themselves to APEL for entry purposes or advanced standing (module exemptions) within a programme. Many students choosing the Foundation degree will not necessarily have pursued the 'normal' pre-university routes to study and therefore careful assessment of the level and nature of their prior learning may be required (Rowley 2005).

Few research studies have specifically focused on higher education lecturers and their perceptions of APEL, despite the fact that it is their academic judgement relied upon to accredit experiential learning. Furthermore, little investigation has been carried out in the context of higher education in further education, even though many students using this route are mature and part time learners in employment. One exception to this was a project on accrediting prior learning carried out by the Higher Education Learning Partnerships (HELP) Centre of Excellence in Teaching and Learning (CETL). This provided 
contextual information about accrediting prior learning in three UPC institutions. This paper builds on this work by reporting findings from a wider survey that sought to explore APEL in this context.

\section{Method}

The survey developed for this study was part of the Partnership Investigations into Accrediting Prior Experiential Learning (Pineapple) project. The Pineapple project is funded by the Joint Information Systems Committee (JISC), as part of the Lifelong Learning and Workforce Development strand of the Institutional Innovation Programme (www.pineappleproject.org.uk). The survey was designed to collect quantitative and qualitative data about two main areas. The first was general awareness of APEL in their institution, including understanding of policy and responsibility for APEL. The second focused upon the support received for APEL as well as the support required. The data from the survey would then be used to inform future research. The survey was created using a web-based survey tool which helped to track responses and monitor individual results.

A draft survey was piloted with six lecturers and this revealed that programme managers were most likely to deal with any enquiries or applications. An additional comment received was that the survey was too long. To shorten it, one section was replaced with two questions with a view to arranging follow up interviews with individuals. It quickly became apparent that some lecturers were responsible for more than one programme at each college. A series of four drop-down menus were provided from which the participant could select their programme(s). Two questions were also added asking when and how students find out about APEL. This was felt to be important for systems development. Finally, two questions about the support for APEL were changed to help distinguish between the support already available to lecturers and the support required.

The final survey was divided into three main sections:

1) Your details;

2) APEL in your institution;

3) Support for APEL. 
Section 1 obtained information on individual lecturers and their roles. Section 2 sought to examine individuals' awareness of APEL policy and practice within their institution. The final section of the survey focused upon the support received and required.

\section{Achieved sample}

The link to the survey was sent out with an accompanying email which explained the purpose of data collection and that all data would remain anonymous. The survey link was sent to 161 Higher Education (HE) in Further Education (FE) programme managers from 18 University of Plymouth partner colleges. A $50 \%(\mathrm{~N}=81)$ response rate was achieved for this study. When respondents were asked how long they had worked at their institution, the response average was 12 years. The 81 respondents worked in 14 different institutions across the partnership, with 28 respondents working at the largest partner further education college. A summary of the characteristics of the institutions is provided below.

(Table 1)

Analysis of the results was undertaken adopting a critical realist approach (Bhaskar 1998). Realists seek to show causal explanations in a social world where structures and processes are constantly changing, making definite prediction impossible. Critical realists believe that there will always be many possible explanations for investigation and that the primary aim of social science is to be critical of the actions that lie behind false explanations (Archer et al. 1998; Scott 2005b). Reflecting this approach, the results are discussed with specific reference to the mechanisms and barriers in place to claim APEL. For example, if agents such as programme managers are to effectively support students then structures need to bring clarity and transparency to the process. This is discussed in relation to government agendas as well as institutional policies and regulations.

\section{Findings}

The results presented below primarily relate to awareness of APEL, APEL in practice and the support requirements for staff. However, they also highlight some of the broader issues 
raised about the perceived purpose and implementation of APEL. Codes assigned to quotations indicate affiliated institution and university faculty. If questions were not answered by all respondents, the number of people that skipped the question has been provided.

\section{Awareness of APEL}

In order to investigate awareness of APEL among lecturers, questions related to general awareness as well as specific aspects of APEL in their institution. When asked whether respondents were aware of APEL in their institution, 69 (85.2\%) respondents answered 'yes' and $12(14.8 \%)$ answered 'no'. This may help to explain why 12 respondents skipped many of the following questions about APEL in their institution. Whilst this first result provides an indication of general knowledge of APEL, it was important to ascertain the extent of awareness. As earlier evidence testified, practice could be limited even when policies existed. In 2000, it was claimed that within HE, APEL 'is now mainstream' (Merrifield et al. 2000). This was based upon the majority of HEls possessing an APEL policy. However, as the report explained:

'The adoption of APEL policies does not mean that there are substantial numbers of students gaining APEL credit'. (Merrifield et al. 2000, 2)

The majority of respondents in this survey (52.2\%) were aware of an institutional APEL policy, although $33(40.6 \%)$ were unsure and 6 (7.2\%) did not know of any such policy.

(Figure 1)

Merrifield and colleagues (2000) reported that larger institutions were more likely to have an APEL policy, but noted that these were also the institutions with the largest proportion of part time students. Of those aware of a policy in this study, most of these respondents were employed at relatively large partner institutions. However, they were not necessarily from those institutions with the most part time or mature students. 
Respondents were invited to indicate whether the APEL policy addressed any related higher education agendas, including widening participation, attracting experienced students, employer requirements and encouraging progression to HE. These agendas were identified following a review of literature (McDermott, Stillwell, Dismore and Witt 2009). The responses are presented in the table below:

(Table 2)

As this shows, the majority of respondents believed that the APEL policy helped to address widening participation, attract experienced students and support the progression of students to HE. There was particular uncertainty among lecturers about whether APEL addressed employer requirements. The reasons for this are unclear, although it might be connected to perceptions that employers are not aware of APEL. Given the increase of work-based learning in universities generally, particularly in the context of the Foundation degree, this might be surprising. Yet, improving links with employers has been an advantage of APEL cited in a number of reports (e.g. NIACE 2008; Leitch 2006).

The study conducted by the Learning from Experience Trust revealed a variation in the way that APEL can be coordinated. HEls were spread on a rough scale from centralised to devolved structures (Merrifield et al. 2000). This survey asked lecturers whether there was a person responsible for supporting students who APEL in their institution. Over half the respondents were unsure (52.9\%). Just under a third $(29.4 \%)$ claimed that there was somebody with responsibility for APEL and $17.6 \%$ confirmed that no one person had responsibility. Of those that answered 'yes', a second question asked them how many people had responsibility for APEL. Most responses stated that the number of people responsible for APEL varied according to the faculty. This suggests that there was no centralised control structure in any of the institutions within this sample. Whilst this offers the potential for widespread ownership, it is arguably harder to maintain consistency and reliability (Trowler 1996). This may be considered to be especially important in a higher education partnership that promotes a shared vision with common values. 
There was some variation in how staff believed students were informed about APEL in their college. A relatively large percentage of responses stated that students found out during discussions with college staff, including tutors or programme managers $(42.5 \%)$ or at interview (22.9\%). A number of responses (10.9\%) suggested that students find out via the college publicity. Some of the lecturers did not know how students find out about APEL (4.9\%). The full list is presented below. Given that most answers indicate that students find out during discussions with lecturers, it seems imperative that staff have all the necessary information at their disposal. Confusion about whether there was somebody ultimately responsible for APEL suggests that not all staff were equipped with accurate information that could help them in this situation. The results also show that many staff relied upon materials issued by the institution to inform students or upon the students themselves to raise it as an enquiry.

(Table 3)

The findings presented here are supported by earlier research. Merrifield and colleagues (2000) also reported that prospectuses and catalogues were the main way students found out about APEL. Indeed, the report showed that whilst a third of the HEls issued APEL guidance for students, $72 \%$ institutions expected students to ask admissions or academic staff. As Johnson (2002) suggested, for APEL to be used, it has to be positioned within the marketing strategy and admissions process of the institution.

An important aspect of a student's decision to APEL is likely to be any cost implications. However, the majority of lecturers in this study were unaware of how much students are charged for APEL (70.6\%) and $17.6 \%$ were unsure. Few respondents $(11.8 \%)$ did know how much APEL cost for students. This was not surprising in the light of the limited research carried out. Merrifield and colleagues (2000) found that most institutions charged a fee for APEL credit and $16 \%$ (of their stage 1 survey, $n=107$ ) did not charge. Overall, Merrifield and colleagues found it very difficult to obtain information on the exact cost of APEL, with institutions appearing to report on different units of credit. In the context of the University of Plymouth, it is the responsibility of partner institutions to set their own fees for APEL and 
to communicate this to staff. Results from this survey suggest that lecturers need to have this decision clarified so that this information can be communicated effectively to students.

\section{APEL IN PRACTICE}

The findings in relation to APEL in practice suggest that lecturers were actually dealing with more requests about APEL than might have been anticipated. Over half $(60.3 \%)$ the respondents reported receiving an APEL enquiry, over a third (35.3\%) had not and a few (4.4\%) were unsure. Indeed, when asked if they had been involved in an APEL application, $50 \%$ of the sample responded that they had been involved in an APEL application and 50\% had not. 35 of the 81 respondents were able to specify the number of applications they had been involved in. Most of these applications had reportedly taken place between 1-3 years ago. The exact details of the applications were to be a focus of future investigation and therefore outside the remit of this paper.

Overall, this response was surprising, not least because informal discussions with colleagues in the partner institutions had suggested a very limited involvement in APEL. For example, a representative of one of the larger institutions had previously stated that they had only dealt with three claims in the last year and that all of these were APCL claims (McDermott et al. 2009). Other research conducted in the UK supports this finding. For example, Gallacher and Feutrie (2003) reported a relative lack of APEL activity in Scotland compared to in France. In England, HEFCE (2003), Challis (2005) and Scott (2010) all reported a low uptake of APEL applications. One possible reason for the finding of this study is that respondents were referring to APEL on entry rather than specifically for credit. An increase in mature and experienced learners attending HE in FE institutions may also be effecting this trend.

\section{SUPPORT FOR APEL}

Findings from earlier research (Merrifield et al. 2000) indicated a heavy reliance upon departmental staff not designated as APEL advisors and a distinct lack of APEL training. To investigate whether this was true of our sample, respondents were asked whether they already received support in specific areas. These areas were chosen to represent all stages of an APEL claim, as described by Stoney (2010). Very few respondents believed that they 
had received 'a lot' of support in any of the areas. The areas for which one or two respondents had received a lot of support were for planning a claim, producing a claim and arranging for assessment. Of those who had received 'some' support, most had been in the areas of advising on APEL and planning a claim. 'A little' support had been provided for a number of respondents in all areas. However, a high number of respondents reported receiving no support and this was noted in relation to all areas, most notably in the monitoring review and evaluation of APEL applications.

(Figure 2)

As part of this question respondents were invited to provide additional information. Most of these comments referred to support available as and when required. For example, one respondent added, 'I'm sure the advice would be there if asked for' (College M, Business School), whilst another noted that, "I would have taken responsibility for this with colleagues and with advice from [the University]' (College J, Education). There were also statements suggesting that support was something that could be improved and made more consistent. For example, one lecturer wrote that, 'It has been variable over the years', suggesting that, 'It is something which I would like to see given a lot more attention' (College $\mathrm{E}$, Health).

(Figure 3)

When asked about the support lecturers wished to receive in relation to APEL, it is interesting to note the high number that wished to have 'some' rather than 'a lot' of support for all stages of APEL. For example, over half the respondents wanted some support with advising on APEL and planning a claim. A number of respondents did not wish for any support for APEL at all and this amounted to between 2-4 responses per option. Of those who did want a lot of support, many of these wished to focus upon assessment of APEL.

To both questions about support, a high percentage of respondents answered that they were unsure whether they either already received or whether they needed particular support. One suggestion was that, 'it would be helpful to have a dedicated person within the 
Institution' (College E, Health). However, other responses were more sceptical about the need for support if demand was low. As one lecturer pointed out, 'unless students are aware of this, and choose to take it up I will continue to get noone asking me to APEL them onto the course, and will need no support!' (College E, Arts). Another comment was that the level of support really, 'depends on how straight forward the APEL claim is' (College K, Health). The need for linking and sharing an understanding of APEL among employers and HEls was highlighted in the National Institute of Adult Continuing Education (NIACE) report to JISC (NIACE 2008). It was envisaged that a shared understanding would make the process more effective and less time consuming.

\section{Future APEL}

A final question asked the respondents to indicate whether they envisaged APEL becoming more popular among their students. Whilst over a third (38\%) did think APEL would become popular, some (18\%) did not think so and the largest proportion (44\%) of respondents were unsure. This is similar to a finding reported by Johnson (2002) who stated that over half the responses did not expect APEL to grow in the coming year.

(Figure 4)

Many additional comments (32) were made relating to this question, all providing further insight into the range of perceptions about future APEL demand. Many of the comments referred to an increase in older learners entering HE with substantial industry experience. For example, as one respondent stated, 'I have a very diverse student cohort many of whom have experience in the industry and who could apply for APEL' (College $\mathrm{E}$, Science and Technology), whilst another added that, 'a large proportion of my students are already working in industry' (College C, Science and Technology). An additional statement suggested that, '[APEL] enables mostly mature students to gain credit for work they have already done' (College E, Science and Technology). This is important if mature, part time learners constitute a growing proportion of the higher education sector in the UK. As HEFCE (2010) reported, of the total number of student entrants for $2009-10,37 \%$ of these were part time. Many of these entrants were older, with 55\% aged 30 and over. 
One respondent related this trend directly to the national economy: 'more mature students coming in from industry. Particularly in this economic climate when there are people who wish to up skill/retrain' (College E, Business School). This reflects an underlying argument for APEL, that education must be relevant to the changing needs of the workforce and economy (Gallacher and Feutrie 2003). Linked to this was an acknowledgement by two of the respondents that students with other commitments and substantial experience may appreciate the opportunity to avoid repeating any learning. As one wrote, 'many of my students are older and have previous relevant qualifications or relevant work experience and do not wish to waste time doing modules in which they are very proficient already' (College C, Business School).

However, many comments added by respondents explained why they did not perceive APEL becoming more popular in future. Some of these were related to a lack of general awareness of APEL among staff and students. One individual simply stated that, '[APEL] has lots of potential but staff have too little time to promote and manage APEL effectively' (College A, Science and Technology). Another pointed out that, 'If I'm not sure what it is how will the learners ever know?' (College E, Arts) One perceived reason for students not choosing the APEL route was that students would rather complete the whole course. As one lecturer stated:

'A lot depends on background experience obviously but most students that we see are wanting a fresh start and feel too much APEL accreditation limits their experience and learning on the course. Often areas that are revisited are done so with fresh eyes and a new context so the experience is different and more up to date.' (College $\mathrm{K}$, Arts)

One additional comment pointed to the difference between APEL and APCL, citing APCL as the more popular option for students. Also, this lecturer agreed with the earlier suggestion that often students prefer to do the whole course: 
'I think APCL is much more likely to occur. Over the 8 years I have acted as Programme Manager I can only think of one student who may have been suitable, and this person declined to make a claim, preferring to complete the relevant area of study in the normal way.' (College $\mathrm{H}$, Science and Technology)

Findings reported elsewhere concur that often students would rather undertake the formal module rather than taking the APEL route, simply because it is easier and because APEL is time consuming (Houston et al. 1997). Another reason is that students wish to maximise learning and engagement with the group. One lecturer was of the opinion that students should be, 'full members of the group' by joining in the whole course:

'We generally prefer students to join in the whole course \& be full members of the group \& have the same developmental experiences. There could always be the exception, however, for their own particular circumstances.' (College K, Science and Technology)

Associated with this was the view that APEL would only be used by students to exempt themselves from part of a programme. For example, as an arts lecturer stated:

'The majority of students that apply for the FdA in Fine Art are not chasing the qualification but what they get from the course. They are therefore not looking to bypass any aspects of the programme through APEL'. (College E, Arts)

This view perhaps reflects the argument posed by Armsby and colleagues (2006). They recognised that HEls are the traditional custodians of high-status knowledge and that it is often difficult for assessors to recognise other forms of knowledge within existing academic and social structures. In a study by Peters (2005), one student discussed the reluctance of lecturers to acknowledge her experience, attributing this to a possessive attitude of academics to the modules they teach. This was in contrast to the lecturers' perceptions of themselves as, 'rigorous but sympathetic and flexible' (Peters 2005, 280). Some members 
of staff appeared to be taking care to consider APEL from the students' point of view. The same lecturer summed up the tension illustrated in the following statement:

'In theory one would expect it to be popular, particularly in business facing programmes, also the handbooks etc do give APEL links to [University of Plymouth] site. However in my experience it is not common. I think there are probably three main reasons for this:-

1. It is not 'sold' up front.

2. Many students are inexperienced with HE institutions and therefore are not sure they 'fit' this.

3. Some may feel that they are well experienced but that it would be a long process of 'picking into them' that they don't require and so if they need the qualification they take the whole thing, but if they can get away without it they do so.' (College $\mathrm{E}$, Science and Technology)

This highlights the potential of APEL in theory and the problems of APEL in practice and emphasises that without a clear understanding of APEL, many students (particularly those considered non-traditional such as part time adult learners) will not have the confidence to attempt an APEL application. In other words, the confusion surrounding APEL is possibly putting off the very students most likely to consider this route. 


\section{Conclusions}

The aim of this survey was to develop a sense of HE lecturers' understanding of APEL. Reflecting the critical realist approach, the perceptions of lecturers about APEL can be discussed with particular reference to contextual factors, as well as perceived mechanisms, barriers and potential outcomes of APEL. This research is paramount if we are to better understand APEL from the point of view of those who accredit learning.

Although many lecturers claimed to have an awareness of APEL, subsequent responses indicated that the main barrier to APEL in practice is limited knowledge. A relatively high number of lecturers (41\%) were unsure about whether an institutional APEL policy existed. Other areas of uncertainty included who was responsible for APEL enquiries and applications in the institution, how students find out about APEL and the financial implications of APEL for students. With such ambiguity, it is unlikely that students can access the necessary information they need in time to make an informed decision. Moreover, this study showed that students are unlikely to find out about APEL, unless lecturers highlight this as a route. However, as one academic pointed out, 'a common response to uncertainty and insecurity is to erect barriers, in this case bureaucratic procedures, in an attempt to ensure that standards are maintained' (Trowler 1996, 26). It appears that little has changed since this time.

Many lecturers in this study agreed that in general, APEL helped to widen participation, served the needs of experienced students and encouraged progression. However, few believed that APEL could address employment requirements. This was surprising given that the QAA (2004) linked APEL with partnership working with business and other organisations such as the Centre for Research in Lifelong Learning (CRLL), have stressed the benefits of APEL for worker flexibility and mobility (CRLL 2002). This perspective was discussed by Garnett and colleagues (2004). They described that at its narrowest, APEL could benefit institutions by widening access to academic courses. However, at its broadest, APEL could serve much wider interests by unlocking, enhancing and making use of previously unrecognised knowledge and skills. Misunderstanding of its purpose is another barrier to 
effective practice. Widespread and full discussion needs to take place in the higher education community if these outcomes are to be realised.

The potential for APEL to be treated as a process for development rather than merely an instrument of recognition (Garnett et al. 2004) seemed largely unrecognised by the lecturers in this study. For example, there was no consideration about the skills required to reflect on experience and connect the learning to specific learning outcomes. Yet, the process of evaluation and reflection is seen by others as empowering the individual and leading to an increase in confidence. Moreover, reflection of this kind is important with regards APCL. Trowler (1996) argues that credit exchange and developmental APEL models should be recognised as a continuum rather than dichotomous. Importantly, this helps to acknowledge the different levels of reflection involved in identifying credit worthy skills. Failing to recognise APEL as a potentially powerful developmental tool offers another possible barrier to APEL, one that could be overcome with appropriate support.

Despite these potential barriers to APEL, many lecturers in this study reported more enquiries and applications than might have been expected. Furthermore, additional comments highlight the potential of APEL for the increasing numbers of mature part time learners who already possess substantial industry experience. This might be partly due to the area of higher education in which these lecturers work. Within the context of the Foundation degree, a vocationally oriented qualification intended to be employer led and to form part of the government's widening participation strategy (Jackson and Jamieson 2009), APEL would seem to offer a great deal. This may be a sign that traditional views of higher level learning are gradually being influenced by developments in work-based learning, making APEL more acceptable (Peters 2005).

It is argued here that to prepare adequately for future changes, the right mechanisms must be in place. Some of the barriers discussed here can be overcome by appropriate support. The results from this survey suggest that at least some level of APEL support is required by lecturers. The majority of respondents were not receiving any support for APEL, some had received a little and others were simply unsure whether support was required at all. If 
demand for APEL is increasing and coordination of APEL in institutions remains devolved, then support for individual programme managers would help to ensure consistency and to maintain standards of quality assurance.

Overall, this paper highlights a tension between recognition of the value that APEL can bring to a specific (and growing) group of students and certain repercussions for the higher education community. One possible repercussion is related to the institution-wide approach to knowledge and what is considered 'acceptable' forms of learning. Whilst HE institutions might recognise that APEL can attract non-traditional learners such as part time adult learners, they may be seeking to maintain their monopoly higher learning and their roles as traditional custodian of high-status knowledge. One concern seems to be that APEL signifies an instrumentalist approach to learning, whereby students' experiences are transformed into a set of saleable assets, through a list of attributes with which they can market themselves. The implication of this, that education is a commodity rather than a process, is potentially damaging to HE and our concepts of learning. This argument has been best summed up in the following extract:

'...we believe that a struggle over what is the nature of knowledge and learning is taking place in relation to APEL. The changes arising from this struggle can be seen as transforming the production, validation and communication of knowledge and reconceptualising the meaning of learning.' (Armsby et al. 2006)

Yet there appear to be practical reasons for addressing the issue of APEL sooner rather than later. As reported by McNair (2009), demographic changes are leading to a growing and ageing population, with most people spending more of their lives outside the labour market. Appropriate opportunities should be provided for people to learn what they need, when they need it, whilst being flexible about taking into account prior experiences. However, as this paper demonstrates, APEL in practice has to be negotiated by higher education staff and appropriate support of these individuals requires attention if they are to effectively guide and nurture the lifelong learner. 


\section{Acknowledgements}

We would like to thank all of the UPC lecturers who took part in the research. This project was funded by the Joint Information Systems Committee (JISC) as part of the Lifelong Learning and Workforce Development strand of the Institutional Innovation Programme.

\section{Notes on contributors}

Harriet Dismore is a Research Fellow at the University of Plymouth. She has worked on a range of research projects investigating the transitions of people in education, including the accreditation of prior learning, progression from further to higher education and transition into employment.

Anne McDermott is a Research Fellow at the University of Plymouth. A Principal Investigator for the Pineapple project, she has also worked on a number of technology enhanced learning projects ranging from the development of Digital Repositories to the use of Web 2.0 supporting work based learners in HE in FE.

Neil Witt is Associate Professor, Head of Technology Enhanced Learning at the University of Plymouth. His role is to lead the development of technology enhanced learning and blended learning across the university. He has lead a range of elearning related projects over the last 15 years, specialising in IPR, accessibility, the use of Web 2.0 and open access repositories.

Robert Stillwell is a Senior Learning Technologist at the University of Plymouth. He has worked on a range of JISC funded projects including Web2.0 technologies, digital repositories and investigating accreditation of prior experiential learning.

Sophie Neville is a Research and Development Assistant at the University of Plymouth. In addition to working on the Pineapple project, she has been involved in work-based learning and placement projects, developing work packages for students and improved promotional materials. 
Mark Stone is the associate dean for teaching and learning with the University of Plymouth Colleges Faculty. Marks' research interests include people management, leadership, organisational learning and change, knowledge management and communities of practice.

\section{References}

Adam, S. 2006. The recognition of prior learning in the context of European trends in higher education and lifelong learning. In C. Corradi, N. Evans and A. Valk. (Eds.), Recognising experiential learning: practices in European universities. Tartu: Tartu University Press.

Archer, M., R. Bhaskar., A. Collier., T. Lawson and A. Norrie (Ed.). 1998. Critical realism: essential reading. London: Routledge.

Armsby, P., C. Costley and J. Garnett. 2006. The legitimisation of knowledge: a work-based learning perspective of APEL International Journal of Lifelong Education, 25, no. 4: 369383.

Bergsteiner, H., G. Avery and R. Neumann. 2010. Kolb's experiential learning model: critique from a modelling perspective. Studies in Continuing Education, 32, no. 1: 29-46.

Bhaskar, R. 1998. The possibility of naturalism ( $3^{\text {rd }}$ edition), London: Routledge.

Butterworth, C. 1992. More than one bite at the APEL, Journal of Further and Higher Education, 16, no.3: 39-51.

Centre for Research in Lifelong Learning (CRLL). 2002. Creating opportunities for APEL: recommendations for change. Glasgow: Centre for Research in Lifelong Learning.

Challis, M. 2005. Challenging issues: the accreditation of prior experiential learning (APEL), Forward 5, Spring, 25

European Centre for the Development of Vocational Training (CEDEFOP). 2009. European guidelines for validating non-formal and informal learning, CEDEFOP.

European Commission. 2001. Making a European Area of Lifelong Learning a Reality, Brussels: European Commission.

Gallacher, J. and M. Feutrie. 2003. Recognising and accrediting informal and non-formal learning in higher education: an analysis of the issues emerging from a study of France and Scotland. European Journal of Education, 38, no. 1: 71-83. 
Garnett, J., D. Portwood and C. Costley. 2004. Bridging rhetoric and reality: accreditation of prior experiential learning (APEL) in the UK, Bolton: University Vocational Awards Council.

Higher Education Finding Council for England (HEFCE). 2010. Foundation degrees: key statistics 2001-02 to 2009-10. London: HEFCE.

Higher Education Finding Council for England (HEFCE). 2003. The Cost of alternative modes of delivery: a study for HEFCE by JM Consulting Ltd. London: HEFCE.

Houston, L., J. Hoover and E. Beer. 1997. Accreditation of prior learning: is it worth it? An evaluation of a pilot scheme. Nurse Education Today, 17, 184-191.

Jackson, S. and A. Jamieson. 2009. Higher education, mature students and employment goals: policies and practices in the UK. Journal of Vocational Education and Training, 61, no. 4: 399-411.

Jamieson, A., R. Sabates., A. Woodley., and L. Feinstein. 2009. The benefits of higher education study for part-time students. Studies in Higher Education, 34, no. 3: 245-262.

Johnson, B. 2002. Models of APEL and quality assurance, Brentwood: Southern English Consortium for Credit Accumulation and Transfer (SEEC).

Kolb, A. and D. Kolb. 2005. Learning styles and learning spaces: enhancing experiential learning in higher education. Academy of Management Learning and Education, 4, no. 2: $193-212$.

Learning from Experience. 2003. The accreditation of prior (experiential) learning: an overview of the theory and practice for $A P(E) L$, http://www.learningexperience.org.uk/downloads/apel-overview.pdf, accessed 09 August 2010.

Leitch, S. 2006. Leitch Review of skills: Prosperity for all in the global economy - world class skills (Final Report). Norwich: HMSO.

McDermott, A., R. Stillwell., H. Dismore and N. Witt. 2009. A baseline study of APEL. A report to the Joint Information Systems Committee, http://www.jisc.ac.uk/media/documents/programmes/institutionalinnovation/workfor cedev/pinapplebaselinereport.pdf, accessed 09 August 2010.

McNair, S. 2009. Demography and Lifelong Learning. IFLL Thematic Paper 1. Leicester: National Institute of Adult Continuing Education. 
Merrifield, J., D. Mclntyre and R. Osaigbovo. 2000. Mapping APEL: Accreditation of prior experiential learning in English higher education, London: Learning from Experience Trust.

National Institute of Adult Continuing Education (NIACE). 2008. Accreditation and recognition of prior experience and learning, JISC Funded Project. Leicester, NIACE.

Peters, H. 2005. Contested discourses: assessing the outcomes of learning from experience for the award of credit in higher education. Assessment \& Evaluation in Higher Education, 30, no. 3: 273-285.

Pitman, T. 2009. Recognition of prior learning: the accelerated rate of change in Australian universities. Higher Education Research and Development, 28, no. 2: 227-240.

Quality Assurance Agency (QAA). 2004. Guidelines on the accreditation of prior learning, Mansfield: QAA.

Rogers, A. 2002. Teaching adults (3rd ed.). Buckingham: Open University Press.

Rowley, J. 2005. Foundation degrees: a risky business? Quality Assurance in Education, 13, no. 1: 6-16.

Scott, D. 2005b. Critical realism and empirical research methods in education. Journal of Philosophy of Education, 39, no.4: 633-646.

Scott, I. 2010. But I know that already: rhetoric or reality the accreditation of prior experiential learning in the context of work-based learning. Research in PostCompulsory Education, 15, no. 1: 19-31.

Scott, I. 2005a. Accreditation of prior learning in a nurse education programme. In J. E. Miller and J. E. Groccia (Eds.), On becoming a productive university: strategies for reducing costs and increasing quality in higher education (pp. 248-255). MI: Anker Press.

Stoney, C. 2009. APEL System. Presentation to the Lifelong Learning Network National Forum on 25th February 2009, http://www.westlondonlln.org/lifelong learning networks/716/IIn-national-forumapel-work-strand?zem contact send article=yes, accessed 09 August 2010.

Trowler, P. 1996. Angels in marble? Accrediting prior experiential learning in higher education. Studies in Higher Education, 21, no. 1: 17-30. 
Winter, R. 2003. The problem of educational levels (part 1), conceptualising a framework for credit accumulation and transfer, Journal of Further and Higher Education, 17, no. 3: 90103. 